\title{
USO DA GEOTECNOLOGIA PARA A ANÁLISE DA PRECIPITAÇÃO EM CUBATÃO (SP): CORRELAÇÃO COM A OCORRÊNCIA DE MOVIMENTOS DE MASSA
}

\author{
USE OF GEOTECHNOLOGY FOR THE PRECIPITATION ANALYSIS IN CUBATÃO (SP): \\ CORRELATION WITH THE OCCURRENCE OF MASS MOVEMENTS
}

\section{Ana Maria CARRASCOSA DO AMARAL, Fábio Augusto Gomes Vieira REIS; Camila Jardinetti CHAVES; Maria Isabel CASTREGHINI DE FREITAS}

Universidade Estadual Paulista. Instituto de Geociências e Ciências Exatas. Avenida 24-A, 1.515 - Bairro Bela Vista. Rio Claro - SP. E-mails: ana.eng.ambiental@hotmail.com; fabio.reis@unesp.br; camila.j.chaves@gmail.com; isabel.freitas@unesp.br

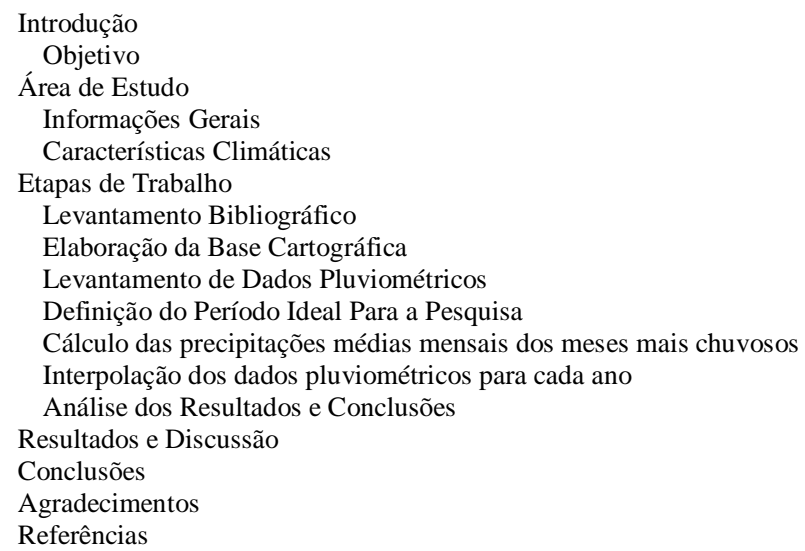

\begin{abstract}
RESUMO - A distribuição espacial e temporal das chuvas é de fundamental importância para gerenciamento dos recursos naturais. A presença de água relaciona-se com a grande maioria dos casos de instabilização de encostas (vertentes), tendo grande influência na deflagração de processos de movimentos de massa. A pesquisa tem como principal objetivo analisar, em ambiente SIG, a variação temporal e espacial da precipitação na região de Cubatão, por meio da interpolação de dados históricos de precipitação intensa na região. Os dados de pluviometria foram coletados por meio do Banco de Dados Hidrológicos do Departamento de Águas e Energia Elétrica (DAEE) do Estado de São Paulo, de forma gratuita. Foram feitos gráficos de média total mensal de precipitação, assim como mapas de distribuição espacial da média da chuva anual. Tais resultados foram comparados com o evento de 1976 ocorrido e registrado em bibliografias. Como resultado, pôde-se observar que o ano de 1975 foi o ano com maiores valores de médias mensais, chegando a quase $650 \mathrm{~mm}$ em janeiro, o que indica que no ano que antecedeu o evento de movimento de massa houve uma chuva acima da média na região, podendo ser um fator considerado deflagrador ou potencializador da ocorrência desses processos geológicos.
\end{abstract}

Palavras-chave: Precipitação; Geotecnologia; Movimentos de Massa.

ABSTRACT - The spatial and temporal distribution of rainfall is of fundamental importance for the management of natural resources. The presence of water is related to the great majority of the cases of instability of slopes (slopes), having great influence in the deflagration of processes of mass movements. The main objective of this research is to analyze the temporal and spatial variation of precipitation in the region of Cubatão by means of interpolation of historical data of intense precipitation in the region. Rainfall data were collected through the Hydrological Data Bank of the Department of Water and Electric Energy (DAEE) of the State of São Paulo, free of charge. Monthly total precipitation average graphs were plotted as well as spatial distribution maps of the mean annual rainfall. These results were compared with the 1976 event that occurred and was recorded in bibliographies. As a result, it could be observed that the year of 1975 was the year with higher values of monthly averages, reaching almost $650 \mathrm{~mm}$ in January, which indicates that in the year before the event of mass movement there was an above average rainfall in the region, and may be a factor considered as a trigger or a potentiator of the occurrence of these geological processes.

Keywords: Precipitation; Geotechnology; Mass Movements.

\section{INTRODUÇÃO}

De maneira geral, a presença de água relaciona-se com a grande maioria dos casos de instabilização de encostas (vertentes), principalmente em ambiente tropical.

Portanto, entre outros fatores, torna-se essencial o conhecimento adequado da dinâmica pluvial nessas áreas que possuem suscetibilidade a ocorrência de movimentos de massa, por meio da distribuição espacial e temporal das chuvas (Souza, 2003).

Nesse contexto, são possíveis dois tipos de abordagens: uma com base na distribuição 
temporal das chuvas, com a finalidade de previsão de acidentes, e outra baseada na sua distribuição espacial, para fins de zoneamentos ou estudos de suscetibilidade (Boin, 2000). No presente trabalho, será utilizada uma abordagem temporal e espacial, uma vez que serão utilizados dados históricos de precipitação, assim como sua distribuição espacial, que serão posteriormente correlacionados com a ocorrência desses fenômenos na área de estudo.

Os movimentos de massa são fenômenos naturais que apesar de serem bastante estudados atualmente, a previsão de sua ocorrência é difícil, uma vez que possuem dinâmicas muito complexas, e mecanismos de ruptura diversos. Estes fenômenos fazem parte da dinâmica externa da superfície terrestre que interage com outros fatores intempéricos e modelam a paisagem.

Além disso, esses movimentos podem ocorrer tanto nas encostas florestadas como em encostas desmatadas e/ou "antropizadas" (Fernandes \& Amaral, 1996). A recorrência dos deslizamentos nas encostas, também chama a atenção, uma vez que estes fenômenos ocorrem frequentemente, porém não na mesma intensidade.

A contínua urbanização associada aos agentes do meio físico e ao ambiente tropical, característica de países como o Brasil, tem proporcionado situações de risco em encostas ocupadas de forma inadequada, gerando prejuízos, tanto no âmbito social, quanto econômico e ambiental.

Segundo Leopold et al. (1964), os trópicos úmidos são considerados como uma das regiões onde as encostas estão mais sujeitas aos movimentos de massa gravitacionais.

As grandes quantidades de chuva e a existência de espessos mantos de alteração são as condições ideais que promovem a ativação destes processos. (Bigarella \& Meis, 1965; Meis \& Xavier da Silva 1968; Fernandes \& Amaral,
1996).

As vertentes úmidas da escarpa da Serra do Mar, onde se insere Cubatão, a área de estudo, possui, pela influência da disposição do relevo, totais pluviométricos anuais que podem variar de $4.000 \mathrm{~mm}$ nas vertentes voltadas para o oceano, até precipitações anuais de $1400 \mathrm{~mm}$ a $1800 \mathrm{~mm}$ nos rebordos interioranos do Planalto Atlântico de São Paulo (Pellegatti, 2007). Segundo Ab'Saber (1986), a área localizada nas vertentes voltadas para o oceano se constitui na "pequena Amazônia", devido à alta pluviosidade.

Nunes (1997), ao se referir à posição geográfica do estado de São Paulo, considera o estado como sendo tropical úmido a subsumido, e os elevados totais pluviométricos seriam consequência direta da atuação dos sistemas intertropicais e extratropicais, conforme também salientou Sant'Anna Neto (1990) em seu trabalho de caracterização dos sistemas atuantes no litoral do estado de São Paulo.

Com a instalação da Cosipa (Companhia Siderúrgica Paulista) em 1953 e do polo petroquímico de Cubatão no final da década de 1960, foram construídos os bairros Cota para abrigar os trabalhadores dos polos industriais. Porém, essas moradias foram construídas ao longo das vertentes inclinadas, sem infraestrutura adequada.

Assim, no final dos anos 1970, o município de Cubatão atingiu condições ambientais preocupantes. Com a dificuldade de dispersão de poluentes, ocorreram chuvas ácidas, degradando a cobertura florestal e tornando constantes os fenômenos de deslizamento de encostas (Pellegatti, 2007).

\section{Objetivo}

A pesquisa tem como principal objetivo analisar, em ambiente SIG, a variação temporal e espacial da precipitação na região de Cubatão, por meio da interpolação de dados históricos de precipitação intensa na região

\section{ÁREA DE ESTUDO}

\section{Informações Gerais}

A área de estudo, Cubatão, localiza-se na latitude $23^{\circ} 50^{\prime}$ a $23^{\circ} 55^{\prime}$ Sul e na longitude $46^{\circ} 30^{\prime}$ Oeste de Greenwich. Possui uma área de aproximadamente $148 \mathrm{~km}^{2}$, e dista $57 \mathrm{~km}$ da capital paulista e 16 km de Santos ou São Vicente. Possui como limites municipais São Bernardo do Campo, Santo André, Santos e São Vicente. A Figura 1 representa a área de estudo.
A região do município é formada por duas províncias geomorfológicas: a área serrana, que compreende uma fração do extenso sistema de escarpas e montanhas que se estende desde o estado do Rio de Janeiro até a porção setentrional do estado de Santa Catarina, e corresponde à borda do chamado Planalto Atlântico; e áreas de planícies, com várias ilhas, correspondendo a fragmentos cristalinos isolados da grande frente de falha e 
rebaixados por erosão, que foi invadida pelo mar, e em seguida foi sendo entulhada por sedimentos. A Baixada Santista, assim, se origina de um antigo

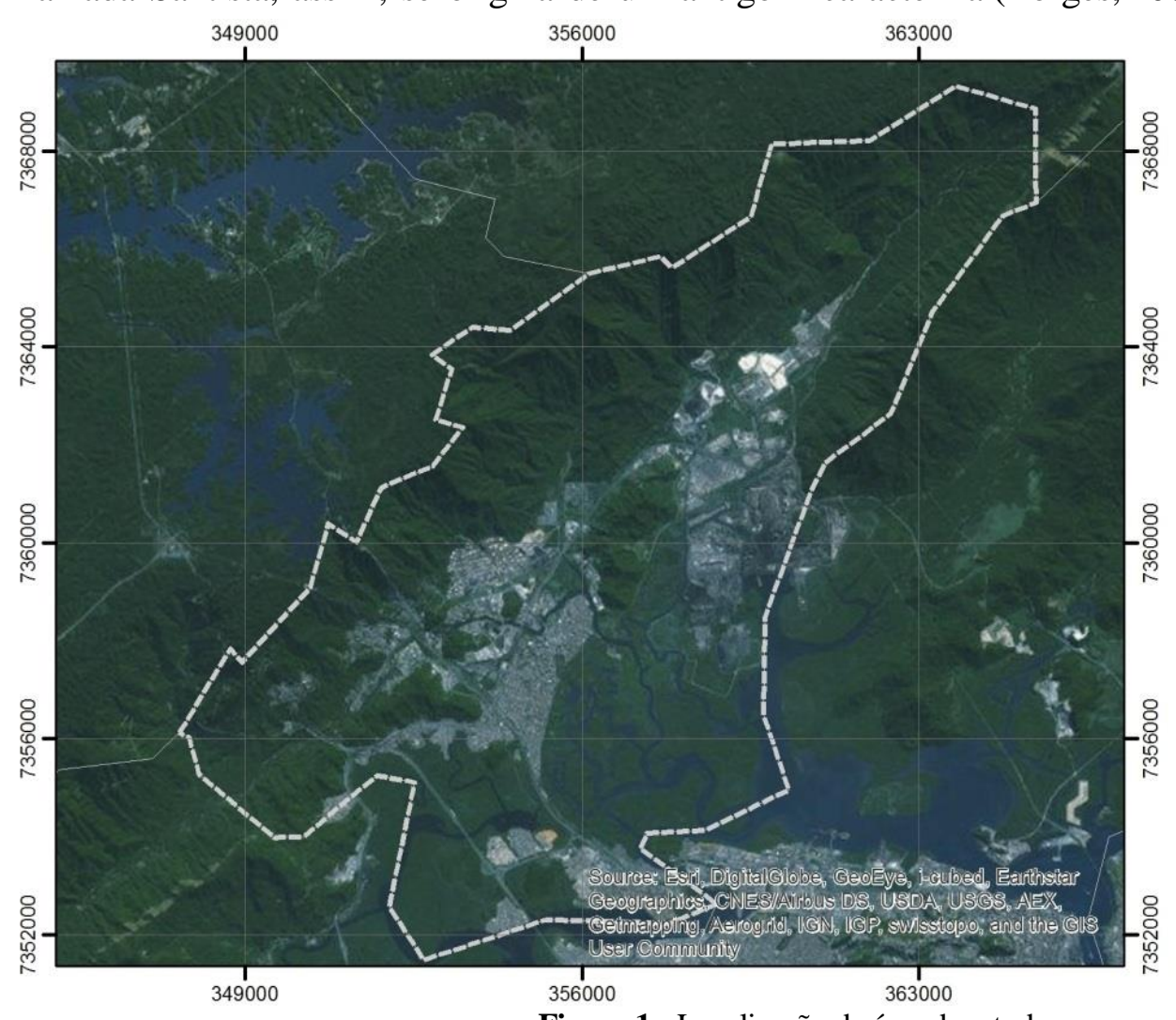

lagamar colmatado, onde a pequena declividade resulta na complexa rede de drenagem que a caracteriza (Borges, 2002).

Figura 1 - Localização da área de estudo.

A vegetação original da área de estudo é conhecida como Floresta Pluvial Tropical Atlântica (Leitão Filho, 1993), atualmente descaracterizada pela ação antrópica, como queimadas, desmatamentos, construções de rodovias, ferrovias, oleodutos, gasodutos e pela poluição atmosférica, que foi agravada pelo polo industrial e petroquímico instalado em Cubatão.

\section{Características Climáticas}

Como o município de Cubatão está geomorfologicamente distribuído nos compartimentos do Litoral e do Planalto Atlântico Sul, ele possui características dos climas regionais úmidos da face oriental e subtropical dos continentes, os quais fazem parte dos climas zonais controlados por massas tropicais e polares (Monteiro, 1973).

Essa influência das massas de ar marítimas e equatoriais (brisa marinha e efeito orográfico) proporciona uma média de umidade relativa anual entre 70 a 90\% (Gutberlet, 1996).

Além disso, devido a esses fatores descritos anteriormente, existe uma variação do índice pluviométrico médio, assim como da temperatura média da região. A precipitação média anual no alto da serra pode chegar a $4.000 \mathrm{~mm}$, enquanto que no sopé da serra, apenas $2.500 \mathrm{~mm}$ (Gutberlet, 1996).

\section{ETAPAS DE TRABALHO}

A pesquisa foi realizada de acordo com as seguintes etapas de trabalho, descritas a seguir.

\section{Levantamento Bibliográfico}

Consiste no levantamento das principais publicações acerca do tema da pesquisa. Foram definidas palavras-chave para a execução do levantamento bibliográfico em bases de dados online. Foram pesquisados artigos nacionais, e eventualmente internacionais, assim como teses e dissertações.
Também foi realizada uma pesquisa acerca dos principais movimentos de massa ocorridos em Cubatão.

As principais palavras-chave definidas foram: Cubatão, distribuição de chuva, análise temporal e espacial da precipitação, precipitação e movimentos de massa, movimentos de massa, análise de séries históricas de precipitação.

Algumas bases de dados que serão utilizadas: Athena (UNESP) - Acervo Geral; Biblioteca 
Digital de Teses e Dissertações da UNESP; USP; Tecnologia; Portal de periódicos da Capes; UERJ; UFRJ; Biblioteca Digital Brasileira de Scientific Electronic Library Online (Scielo); Teses e Dissertações do Ministério da Ciência e GeoScienceWorld e Scopus.

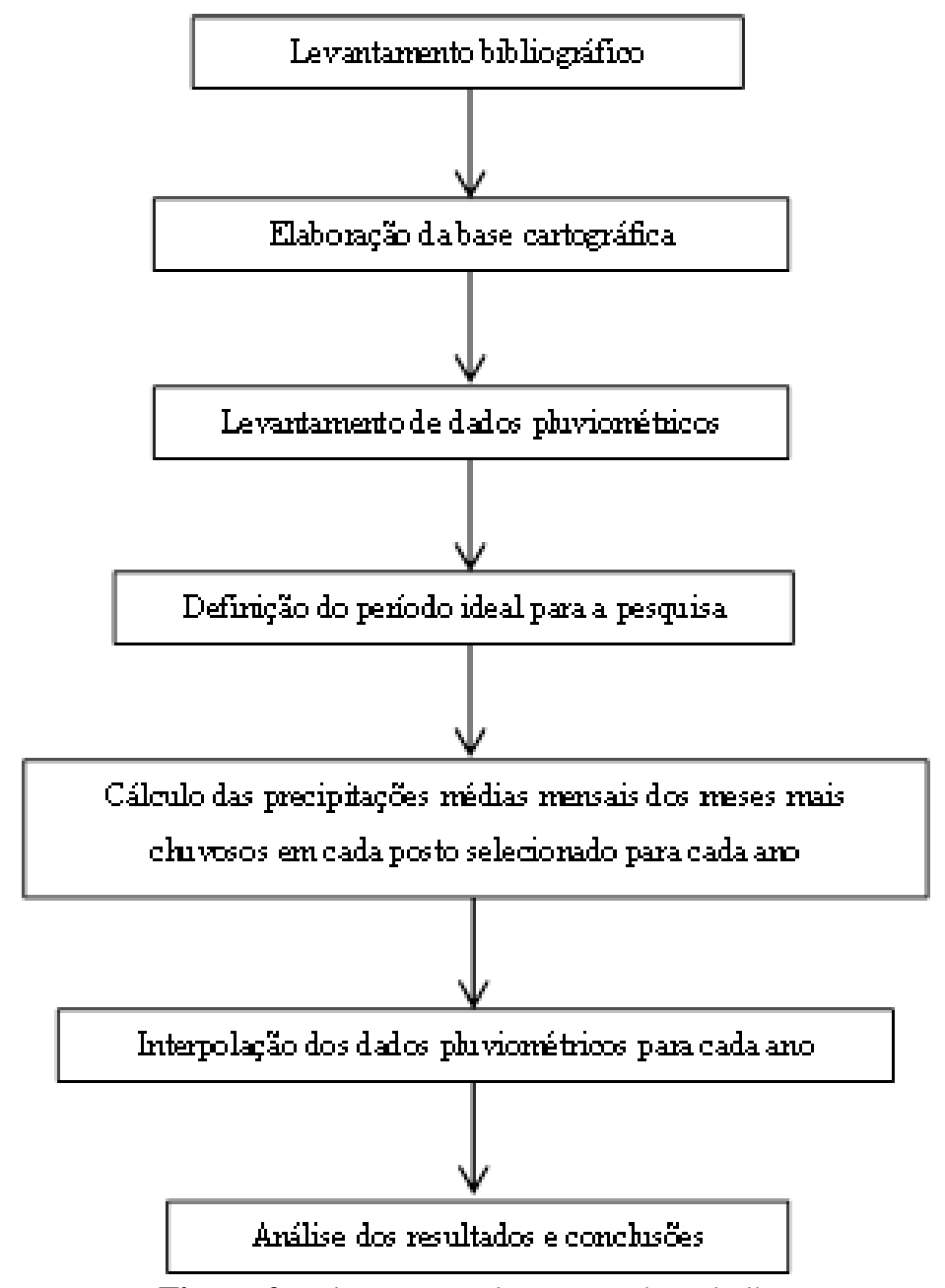

Figura 2 - Fluxograma das etapas de trabalho.

\section{Elaboração da Base Cartográfica}

Foram coletados os dados dos limites dos estados e municípios brasileiros que estão disponíveis no site do Instituto Brasileiro de Geografia e Estatística (IBGE).

Para a elaboração da base cartográfica, primeiramente foi feito o download da SRTM (Shuttle Radar Topography Mission). Essas imagens SRTM foram obtidas por meio de uma missão espacial projetada e financiada pela Agência Espacial Americana (Nasa), Agência Americana de Inteligência Aeroespacial (NGA), em colaboração com a Agência Espacial Italiana (ASI) e o Centro Aeroespacial Alemão (DLR). Foi feito o download das imagens de altitude numérico, com resolução espacial de 30 metros, por meio do Banco de Dados Geomorfométricos do Brasil, disponibilizados pelo site do Instituto Nacional de Pesquisas Espaciais (INPE).

Foram geradas curvas de nível com equidistância de 80 metros por meio da ferramenta Contour disponível no Spatial Analyst do software ArcMap 10.1®. Cabe ressaltar que esta interpolação foi realizada de modo a representar o relevo da área de estudo.

Como as imagens SRTM vieram com projeção cartográfica WGS 1984, foi feita a transformação geodésica para o sistema de coordenadas SIRGAS 2000 (Sistema de Referência Geocêntrico para as Américas), que desde 25 de fevereiro de 2015 é o único sistema geodésico de referência oficialmente adotado no Brasil. A transformação foi feita por meio dos parâmetros de transformação de Molodensky, apresentados na Tabela 1.

Tabela 1 - Parâmetros de transformação geodésica.

\begin{tabular}{c|c}
\hline WGS 1984 & SIRGAS 2000 \\
\hline Translação $\mathbf{X}$ & $-0,478$ metros \\
\hline Translação $\mathbf{Y}$ & $-0,491$ metros \\
\hline Translação $\mathbf{Z}$ & 0,297 metros \\
\hline
\end{tabular}


Também foi gerado um mapa hipsométrico da área de estudo por meio da geração de um Modelo Digital do Terreno (MDT). Para a geração do MDT, foi utilizado o TIN (Triangulated Irregular Network), que é uma estrutura de dado digital elaborado a partir da interpolação dos valores de altitude (curvas de nível) por meio da criação de triângulos entre uma linha e outra, gerando assim um modelo matemático com valores altimétricos. Em suma, o arquivo TIN representa o espaço a partir de um conjunto de triângulos com tamanhos variados, e é gerado a partir das curvas de nível e/ou pontos cotados. No ArcMap 10.1®, a ferramenta para geração deste tipo de dado é o "Create TIN" (Amaral, 2014).

\section{Levantamento de Dados Pluviométricos}

Os dados de pluviometria foram coletados por meio do Banco de Dados Hidrológicos do Departamento de Águas e Energia Elétrica (DAEE) do Estado de São Paulo, de forma gratuita. A pesquisa e download foram feitos pelo site do DAEE. Foram coletados os dados pluviométricos dos poços do município de Cubatão e também dos municípios ao entorno, conforme o quadro apresentado na Figura 3.

\begin{tabular}{|c|c|c|c|c|c|}
\hline ID & Município & Prefixo & Nome & Coord X & Coord Y \\
\hline 1 & CUBATAO & E3-038 & PIACAGUERA & 359145,829 & 7359847,111 \\
\hline 2 & CUBATAO & E3-101 & CUBATAO & 355769,763 & 7357967,961 \\
\hline 3 & CUBATAO & E3-104 & $\begin{array}{l}\text { TERCEIRO PLANO DA } \\
\text { SERRA NOVA }\end{array}$ & 365866,251 & 7367293,935 \\
\hline 4 & CUBATAO & E3-153 & CURVA DA ONCA & 348981,454 & 7357898,391 \\
\hline 5 & CUBATAO & E3-236 & PILOES & 347303,931 & 7356034,864 \\
\hline 6 & $\begin{array}{c}\text { SAO BERNARDO DO } \\
\text { CAMPO }\end{array}$ & E3-109 & ALTO DA SERRA & 347245,246 & 7361571,754 \\
\hline 7 & $\begin{array}{c}\text { SAO BERNARDO DO } \\
\text { CAMPO }\end{array}$ & E3-142 & RECALQUE ABC & 343730,532 & 7372609,203 \\
\hline 8 & $\begin{array}{c}\text { SAO BERNARDO DO } \\
\text { CAMPO }\end{array}$ & E3-244 & RIO ACIMA & 338736,824 & 7363325,058 \\
\hline 9 & SANTOS & E3-041 & CAETE & 376133,921 & 7358157,465 \\
\hline 10 & SAO VICENTE & E3-056 & SAO VICENTE & 360950,188 & 7348790,194 \\
\hline 11 & SAO VICENTE & E3-064 & SALES DA CRUZ & 350716,834 & 7354224,849 \\
\hline 12 & SAO VICENTE & E3-066 & GASPAR RICARDO & 347382,354 & 7348652,291 \\
\hline 13 & SAO VICENTE & E3-228 & HUMAITA & 352451,384 & 7350551,131 \\
\hline 14 & SANTO ANDRE & E3-037 & PARANAPIACABA & 367547,451 & 7369155,091 \\
\hline 15 & SANTO ANDRE & E3-149 & CAMPO GRANDE & 362434,959 & 7370953,091 \\
\hline
\end{tabular}

Figura 3 - Dados de postos pluviométricos coletados (coordenadas em UTM).

Cabe ressaltar que, para a realização do download dos dados em formato de tabela, foram selecionados os postos pluviométricos que possuem pelo menos 30 anos de série histórica. Aqueles que possuíam poucos anos foram descartados, resultando num total de 15 postos.

\section{Definição do Período Ideal Para a Pesquisa}

Com base no levantamento sobre os eventos de escorregamentos e movimentos de massa ocorridos em Cubatão, foram levantadas as seguintes datas na Figura 4, nas quais esses eventos ocorreram.

Tendo em vista essas datas e as séries históricas de precipitação levantadas na etapa anterior, foram selecionados 4 anos para fazer a interpolação e a análise proposta na pesquisa. Os anos selecionados foram: 1973, 1975, 1980 e 1983. 


\begin{tabular}{|c|c|c|}
\hline Data & Vertentes & Volume de sedimentos $\left(\mathbf{m}^{\mathbf{3}}\right)$ \\
\hline $29 / 01 / 1976$ & R. Cachoeira & 156.000 \\
\hline $28 / 01 / 1976$ & Braço Norte & 62.000 \\
\hline
\end{tabular}

Figura 4 - Eventos de movimentos de massa ocorridos na região de Cubatão. Fonte: Massad et al. (1997, 1998).

Cálculo das Precipitações Médias Mensais dos Meses Mais Chuvosos

Nesta etapa, foram selecionados os valores pluviométricos dos meses mais chuvosos da área de estudo (janeiro, fevereiro, novembro e dezembro) para a análise espacial da precipitação média intensa, e a média foi calculada para cada posto, em cada ano, conforme apresentado na Figura 5. Ressalta-se que também foram utilizados os dados de todos os meses para a análise temporal da precipitação.
As cores vermelhas representam os postos com maiores valores de precipitação para aquele ano, as cores amarelas e laranja claro os de precipitações médias, e as cores no tom de verde representam os menores valores de chuva. Essa escala de cores foi utilizada para facilitar a visualização dos postos cujos valores de chuva são altos ou baixos, evitando assim, que qualquer informação discrepante seja considerada na análise.

\begin{tabular}{|c|c|c|c|c|}
\hline \multirow{2}{*}{ Posto } & \multicolumn{4}{|c|}{ Precipitação média mensal dos meses } \\
& mais chuvosos (mm) \\
\cline { 2 - 5 } & $\mathbf{1 9 7 3}$ & $\mathbf{1 9 7 5}$ & $\mathbf{1 9 8 0}$ & 1983 \\
\hline 1 & 301,950 & 520,675 & 337,975 & 194,100 \\
\hline 2 & 388,675 & 509,050 & 312,600 & 290,725 \\
\hline 3 & 341,450 & 540,300 & 302,500 & 300,1 \\
\hline 4 & 501,025 & 709,625 & 424,267 & 207,700 \\
\hline 5 & 453,375 & 727,975 & 395,100 & 364,075 \\
\hline 6 & 463,200 & 651,500 & 399,975 & 302,725 \\
\hline 7 & 252,075 & 264,325 & 260,050 & 172,775 \\
\hline 8 & 318,350 & 317,175 & 343,700 & 232,725 \\
\hline 9 & 390,375 & 632,500 & 324,200 & 317,075 \\
\hline 10 & 416,025 & 436,400 & 284,275 & 235,275 \\
\hline 11 & 478,375 & 830,450 & 320,100 & 362,100 \\
\hline 12 & 496,825 & 689,500 & 356,900 & 355,767 \\
\hline 13 & 438,850 & 481,550 & 305,833 & 270,875 \\
\hline 14 & 413,750 & 552,300 & 416,400 & 266,225 \\
\hline 15 & 345,800 & 458,025 & 399,275 & 252,725 \\
\hline
\end{tabular}

Figura 5 - Tabela com as médias pluviométricas dos meses mais chuvosos de cada ano.

Interpolação dos Dados Pluviométricos Para Cada Ano

Os dados de média mensal dos meses mais chuvosos, conforme apresentados no item anterior da pesquisa, foram inseridos numa planilha do Excel e exportados para o ArcMap $10.1 \circledR$. Deste modo, gerou-se um arquivo do tipo shapefile, contendo pontos com esses valores médios de precipitação em sua tabela de atributos.

Em seguida, foi utilizada a ferramenta Topo to raster do módulo Spatial Analyst do mesmo software, que gerou uma superfície de valores para toda a área.

A classificação desses valores para cada ano foi realizada pelo método Natural Breaks (quebras naturais). Neste método, os intervalos são determinados por meio de um método estatístico, de forma que a variância dentro de cada classe é minimizada, fornecendo categorias que apresentam valores mais homogêneos possíveis dentro das classes. Desta forma, o erro é reduzido, permitindo uma representação mais verdadeira dos dados. Neste método, o número de classes precisa ser definido pelo especialista executor. Nessa pesquisa, 9 foi o número de classes que apresentou melhor resultado, e foi selecionado por meio de testes com outros valores, sem um critério específico.

\section{Análise dos Resultados e Conclusões}

Finalmente, a última etapa consistiu na análise das variações de distribuição das médias de chuvas intensas, correlacionando com o ano que ocorreram desastres (1976). 


\section{RESULTADOS E DISCUSSÕES}

O mapa hipsométrico representa o relevo através de curvas de nível, no qual os espaços entre elas são coloridos segundo uma escala convencional, geralmente as cores verdes representam baixas altitudes e as cores em castanho as altas altitudes. $\mathrm{Na}$ área de estudo, conforme representado na Figura 6, nota-se a diferença de altitude entre o planalto, a noroeste da área, e a planície, a sudeste. Nos locais representados pela Serra do Mar, as altitudes chegam a 900 metros, enquanto que na planície, não passa de 100 metros.

Foram coletados dados de 15 postos pluviométricos distribuídos no município de estudo, assim como nos municípios do seu entorno. Como resultado, foram gerados os seguintes gráficos de chuva para cada ano selecionado para a análise.
Com base nos gráficos, pode-se observar que o ano de 1975 foi o ano com maiores valores de médias mensais, chegando a quase $650 \mathrm{~mm}$ em janeiro. Também se nota que existe uma variação bastante grande da precipitação, chegando de 189 a $832 \mathrm{~mm}$. Tal resultado indica que no ano que antecedeu o evento de movimento de massa houve uma chuva acima da média na região. Em dezembro de 1975, um mês antes do ocorrido, houve uma chuva média de quase $600 \mathrm{~mm}$, sendo um valor bem superior que nos outros anos.

De modo geral, considerando os anos de 1973 e 1975 (barras vermelha e azul no gráfico), houve um aumento no valor de precipitação nos meses de janeiro, fevereiro, novembro e dezembro. No entanto, observando-se os anos de 1980 e 1983, houve o oposto, a precipitação média diminuiu de um ano para o outro.
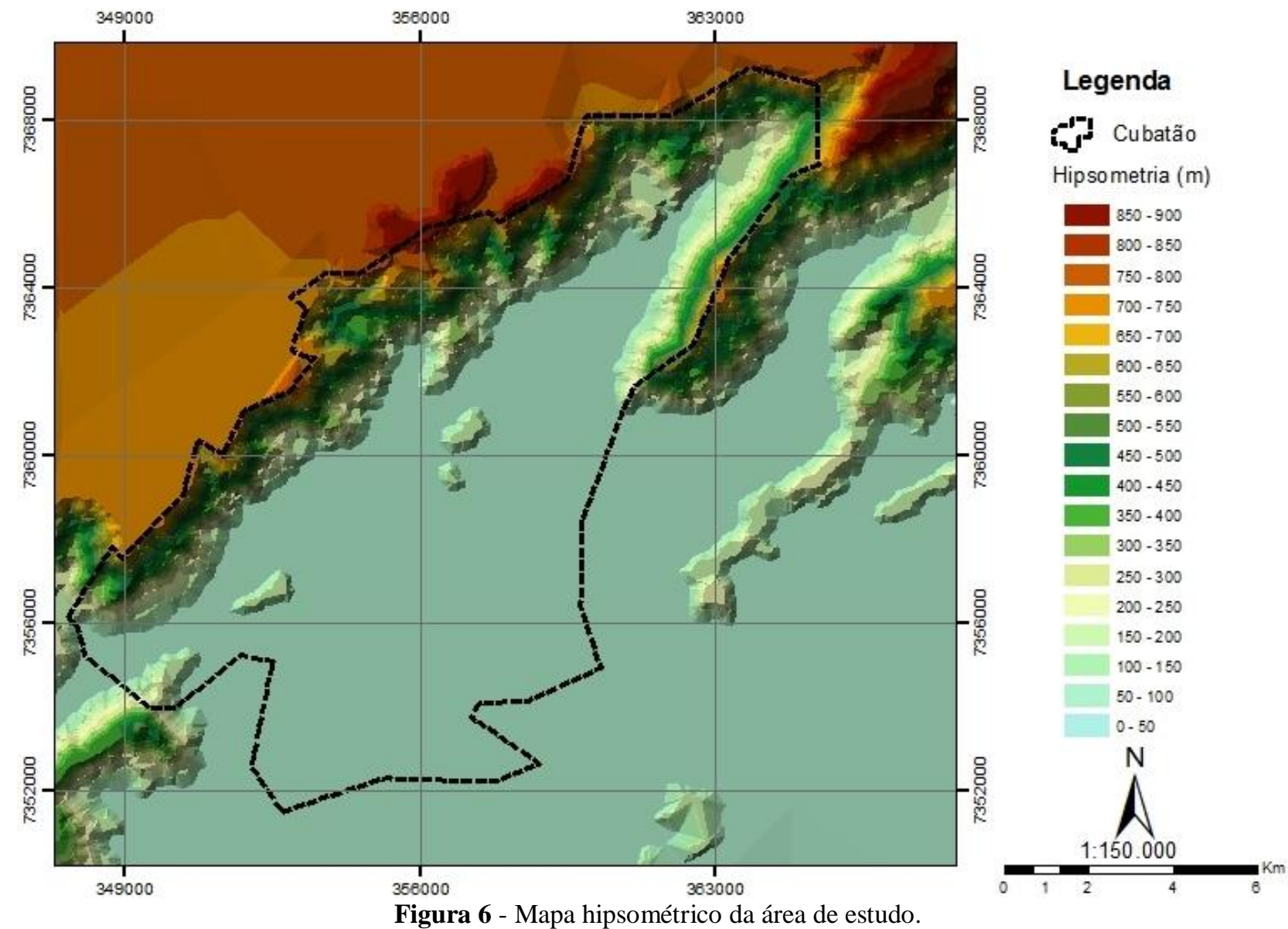

Os mapas de distribuição espacial da precipitação média foram feitos selecionando-se apenas os meses mais chuvosos da área de estudo.

Na Figura 8, que apresenta os dados de 1973, observa-se que a precipitação varia de 225 a 502 $\mathrm{mm}$, sendo as maiores precipitações distribuídas na porção sudoeste da área de Cubatão. As menores precipitações encontram-se na porção central e nordeste.

Em 1975, observa-se que os maiores valores de precipitação estão localizados a sudoeste da área de estudo, e os menores nas porções nordeste e sudoeste. Na parte central, a precipitação foi média.

No ano de 1980, nota-se uma distribuição da São Paulo, UNESP, Geociências, v. 39, n. 1, p. 91 - 100, 2020 
precipitação um pouco distinta das duas anteriores. A variação dos valores é pouco significativa, indo de 245 a $447 \mathrm{~mm}$. Quanto à sua distribuição, os maiores valores estão nas porções oeste e nordeste da região estudada, enquanto que os menores valores se encontram nas porções noroeste e sudeste.

No ano de 1983, nota-se que também ocorre uma baixa variação dos valores de precipitação média dos meses chuvosos, indo de 151 a 388 mm. Foi o ano com menor média de precipitação. A distribuição espacial da precipitação é semelhante ao ano de 1980, sendo as maiores chuvas localizadas a sudoeste e nordeste, e as menores chuvas a noroeste e sudeste, assim como na parte central.

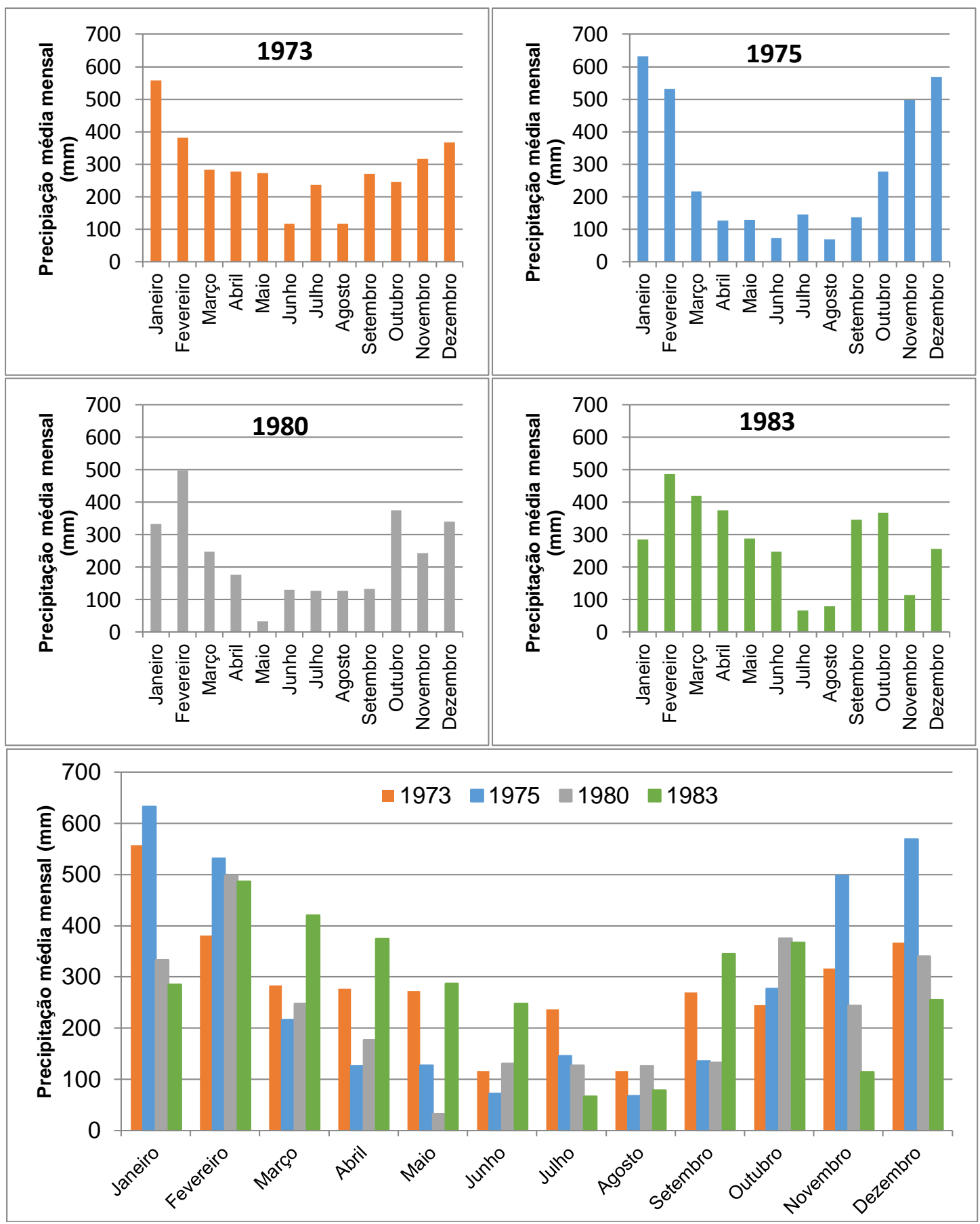

Figura 7 - Gráficos de média mensal para cada ano de estudo.

\section{CONCLUSÕES}

Com base nos resultados apresentados e a exatidão dos resultados depende da discutidos, conclui-se que a metodologia se consistência dos dados que foram utilizados. mostrou eficiente para se atingir o objetivo Como fator determinante para a não proposto da pesquisa. Porém, cabe ressaltar que confiabilidade de um dado de posto 
pluviométrico, pode-se citar problemas com os aparelhos de registro e/ou com o operador do posto. Embora boa parte banco de dados do DAEE esteja disponível atualmente no site do DAEE, gratuitamente, é importante ressaltar que grande parte dos dados é apresentada como não tendo sido consistida.

De modo geral, pôde-se concluir que a distribuição da precipitação média nos meses de novembro a fevereiro segue um padrão semelhante para os 4 anos selecionados para análise, sendo as regiões oeste, sudoeste e nordeste com maiores valores, e as regiões restantes com valores menores. Tal resultado vai ao encontro do que foi levantado pela
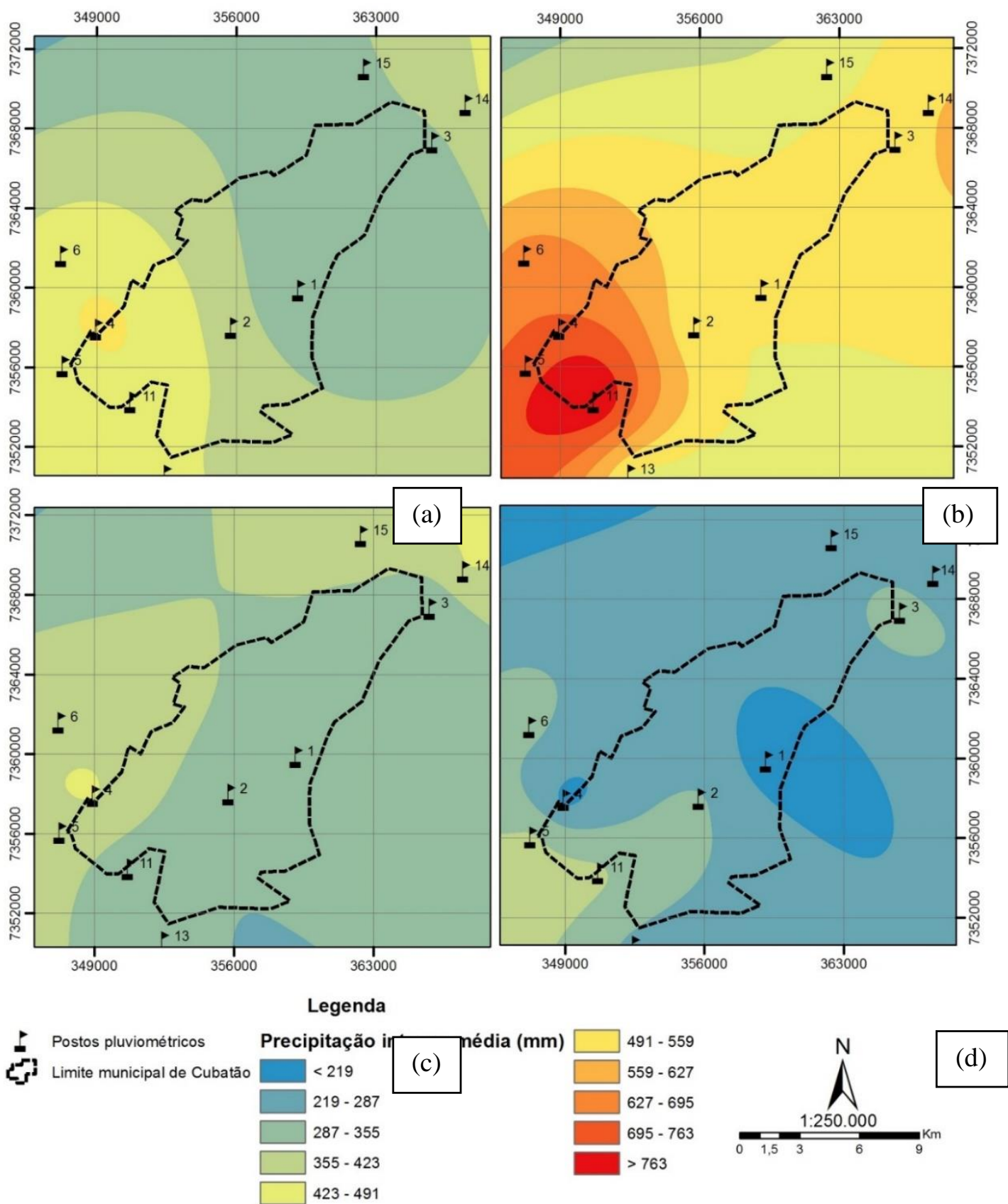

Figura 8 - Mapas de distribuição da precipitação intensa média na área de estudo para os anos estudados. a) 1973, b) 1975 , c) 1980 e d) 1983.

São Paulo, UNESP, Geociências, v. 39, n. 1, p. 91 - 100, 2020 


\section{AGRADECIMENTOS}

O presente trabalho foi realizado com apoio da Coordenação de Aperfeiçoamento de Pessoal de Nível Superior - Brasil (CAPES) - Código de Financiamento 001. Agradeço o pessoal da PósGraduação em Geociências e Meio Ambiente de Rio Claro.

\section{REFERÊNCIAS}

AB'SABER, A.N.O. O tombamento da Serra do Mar no estado de São Paulo. Revista do Patrimônio Histórico e Artístico Nacional, n 21. Rio de Janeiro, p. 7-20, 1986.

AMARAL, A.M.C. Zoneamento Geoambiental do município de Casa Branca (SP). Rio Claro. 2014. Dissertação (Mestrado), Universidade Estadual Paulista.

BIGARELLA, J.J. \& MEIS, M.R.M. Considerações a respeito dos terraços fluviais, rampas de colúvios e várzeas. Boletim Paranaense de Geografia, Curitiba, n. 16/17, p. 153-197, 1965.

BOIN, M.N. Chuvas e Erosões no Oeste Paulista - uma análise climatológica aplicada. Rio Claro. 2000. Tese (Doutorado em Geociências), Universidade Estadual Paulista.

BORGES, W.R.; BRAGA JR., J.C.; TORRES, F.R. O que você precisa saber sobre Cubatão. Cubatão: Design \& Print (com apoio do Arquivo Histórico Municipal de Cubatão), 2002.

DEPARTAMENTO DE ÁGUAS E ENERGIA ELÉTRICA DAEE. Banco de Dados Hidrológicos. Disp. em < http://www.hidrologia.daee.sp.gov.br/ > Acesso em 01 de jun de 2015.

FERNANDES, N.F. \& AMARAL, CP. Movimentos de massa: uma abordagem geológico-geomorfológica. In: GUERRA, A.J.T.; CUNHA, S.B. (Eds.). Geomorfologia e meio ambiente. Rio de Janeiro: Bertrand, p. 123-194, 1996.

GUTBERLET, J. Cubatão: desenvolvimento, exclusão social e degradação ambiental. São Paulo: Edusp, 244 p.1996.

INSTITUTO BRASILEIRO DE GEOGRAFIA E ESTATÍSTICA - IBGE. Dados vetoriais do mapeamento sistemático. Disp.

em <http://www.ibge.gov.br/home/geociencias/default_prod.shtm \#TOPO> Acesso em 4 junho 2015.

ISTITUTO NCAIONAL DE PESQUISAS ESPACIAIS - INPE. Banco de Dados Geomorfométricos do Brasil. Disp. em $<$ http://www.dsr.inpe.br/topodata/dados.php> Acesso em 3 de junho 2015.

LEITÃO FILHO, H.F. Ecologia da Mata Atlântica em Cubatão (SP). São Paulo, Editora da UNESP e Editora da UNICAMP, 194 p. 1993.

LEOPOLD, L.B.; WOLMAN, M.G.; MILLER, J.P. Fluvial processes in Geomorphology. São Francisco, W.H. Freeman, 1964.
MASSAD, F.; CRUZ, P.T.; KANJI, M.A. Comparison between estimated and measured debris flow discharges and volume of sediments. In: $2^{\text {nd }}$ PANAM. SYMP. LANDSLIDES, 2 COBRAE. Rio de Janeiro. 1997. Actas... Rio Janeiro, 1997, p.213-222.

MASSAD, F.; KANJI, M. A.; CRUZ, P. T.; UEHARA, K.; ISHITANI, H.; ARAUJO FILHO, H. A."Debris Flows" em Cubatão, São Paulo: Obras de Controle e Impactos Ambientais. In: CONGRESSO BRASILEIRO DE MECÂNICA DOS SOLOS E ENGENHARIA GEOTÉCNICA XI COBRAMSEG, XI. Brasília, 1998. Anais... Brasília, 1998, v. 2. p. $1265-1272$.

MEIS, M. R. M. \& XAVIER DA SILVA, J. Considerações geomorfológicas a propósito dos movimentos de massa ocorridos no Rio de Janeiro. Revista Brasileira de Geografia, Rio de Janeiro, v. 30, n. 1, p. 55-73. 1968.

MONTEIRO, C.A.F. A dinâmica climática e as chuvas no Estado de São Paulo - estudo geográfico sob forma de atlas. São Paulo: Instituto de Geografia, Universidade de São Paulo, 1973.

NUNES, L.H. Distribuição espaço-temporal da pluviosidade no estado de São Paulo: variabilidade, tendências, processos intervenientes. São Paulo. 1997. 192 p. Tese (Doutorado), Escola politécnica da Universidade de São Paulo. Departamento de Engenharia de Transportes.

PELLEGATTI, C.H.G. Avaliação espaço-temporal da precipitação no perfil da Baixada Santista - Vertentes Oceânicas-Rebordo Interiorano da escarpa da Serra do Mar - SP. São Paulo. 2007. Dissertação (Mestrado em Geografia Física), Faculdade de Filosofia, Letras e Ciências Humanas- Universidade de São Paulo.

SANT'ANNA NETO, J.L. Ritmo Climático e as chuvas na zona costeira paulista. São Paulo, 168 p. 1990. Dissertação (Mestrado), Faculdade de Filosofia, Letras e Ciências Humanas da Universidade de São Paulo. 